\title{
Pediatric Head Trauma
}

\author{
Nicole Sharp ${ }^{1}$ Kelly Tieves ${ }^{2}$ \\ ${ }^{1}$ Department of Surgery, Children's Mercy Hospital and Clinics, Kansas \\ City, Missouri, United States \\ 2 Department of Pediatrics, Critical Care Medicine, Children's Mercy \\ Hospital and Clinics, Kansas City, Missouri, United States \\ Address for correspondence Nicole Sharp, MD, Department of \\ Pediatric Surgery, Children's Mercy Hospital and Clinics, 2401 \\ Gillham Road, Kansas City, MO 64108, United States \\ (e-mail: Nicole.sharp.md@gmail.com).
}

J Pediatr Intensive Care 2015;4:47-54.

\author{
Abstract \\ Keywords \\ - pediatric \\ - children \\ - head trauma \\ - concussion \\ - traumatic brain injury \\ Traumatic brain injury (TBI) refers to a spectrum of brain injury that can result in \\ significant morbidity and mortality in pediatric patients. Pediatric head trauma is \\ distinct from adult TBI. The purpose of this review article is to discuss pediatric TBI and \\ current treatment modalities available.
}

\section{Introduction}

Traumatic brain injury (TBI) is a broad term referring to any traumatic injury of the brain. It is a significant cause of morbidity and mortality in both adult and pediatric patients. TBI encompasses a broad spectrum of injuries from mild head injury, including concussion, to severe head injury.

\section{Epidemiology and Etiology}

Head trauma is the leading cause of death and disability in children older than the age of 1 year. $^{1-3}$ In the United States, approximately 1.7 million TBI's occur annually, with nearly 52,000 deaths and 275,000 hospitalizations. ${ }^{4,5}$ These figures commonly underestimate the true incidence of traumatic brain injuries as they often fail to include those patients who suffer from concussions. The Centers for Disease Control and Prevention estimate approximately 3.8 million concussions occur annually in the United States. ${ }^{6}$ There are nearly half a million emergency department visits annually for children younger than 14 years because of TBI, with males between the ages of 0 and 4 years having the highest rates of TBI-related emergency department visits, hospitalizations, and deaths. ${ }^{5}$ There appears to be a bimodal distribution in the severity of TBI with the first peak occurring between birth and 4 year of age and the second between 15 to 19 years. In the United
States, males are typically more likely to suffer a TBI by a ratio of nearly two to one. ${ }^{5,7-9}$

\section{Pathophysiology}

The Monro-Kellie doctrine dictates that the sum of the brain, cerebral spinal fluid, and blood is a fixed equilibrium within the cranium so that a change in volume of any of the constituents must be compensated by a decrease in another. The relationship between a change in intracranial pressure $(\triangle \mathrm{ICP})$ and change in volume $(\Delta \mathrm{V})$ is exponential. The initial response to acute increases in volume is well compensated spatially with little change in ICP. The cerebrospinal fluid, for instance, is displaced into the spinal canal. As the ICP approaches $25 \mathrm{~mm} \mathrm{Hg}$, the compensatory mechanisms can no longer accommodate any further increases in intracranial volume and the ICP rises exponentially with major increases in ICP with even small increases in $\Delta \mathrm{V}$.

Although the Monro-Kellie doctrine applies to all patients, the pediatric brain is structurally distinct from the adult brain, which may explain differences in response to injury. In the first 6 months of life, the brain doubles in size and reaches approximately $80 \%$ of its final size by the age of 2 years. Children have higher brain water content, the calvarium is relatively large in proportion to the rest of the body, the vasculature is more tenuous, there is incomplete neuronal received

September 1, 2014 accepted after revision December 20, 2014
Issue Theme Management of Children with Trauma in the PICU; Guest Editor: Pablo Aguayo, MD
DOI http://dx.doi.org/ 10.1055/s-0035-1554989. ISSN 2146-4618.
Copyright $\odot 2015$ by Georg Thieme Verlag KG, Stuttgart · New York 
synapse formation, and the pediatric brain has less myelination as compared with adults. ${ }^{9,10}$ The subarachnoid space is also smaller resulting in less protection than the adult brain because of the less buoyancy resulting in higher susceptibility to injury with changes in head momentum. While some argue that an open fontanelle may be protective as it allows for expansion of intracranial content during pressure increases, others have shown that the smaller neural axis of children may result in a decrease in compliance of the pressurevolume relationship with intracranial hypertension. ${ }^{11,12}$ Adult cerebral blood flow (CBF) is typically 50 to $55 \mathrm{~mL} /$ $100 \mathrm{~g}$ of brain tissues/minute while pediatric levels vary significantly by age. At the age of 1 year, $\mathrm{CBF}$ approximates adult levels. At the age of 5 years, CBF is approximately $90 \mathrm{~mL} /$ $100 \mathrm{~g} / \mathrm{min}$ and gradually declines to adult levels by the midlate teenage years. ${ }^{13-21}$ TBI can result in significant prolonged decreases in $\mathrm{CBF}$, which may be inadequate to meet normal pediatric metabolic brain demands resulting in regional and possibly even global cerebral ischemia. ${ }^{13-21}$

While CBF is still considered experimental and is not readily measurable without the use of transcranial Doppler or xenon-enhanced computed tomography (CT) imaging, ${ }^{12-14}$ cerebral perfusion pressure is easily calculated at the bedside and can be used to guide clinical decision making in the care of the patients with TBI. Cerebral perfusion pressure is the transmural pressure gradient, which is the driving force required to supply cerebral metabolic needs and is calculated by the difference between the mean arterial pressure and the ICP. In patients with intact cerebral autoregulation, there is correlation between cerebral perfusion pressure (CPP) and $\mathrm{CBF} .{ }^{16}$ Cerebral autoregulation is a homeostatic process that results in maintenance of $\mathrm{CBF}$ over a wide range of mean arterial pressures. Vessels vasodilate and vasoconstrict as needed to maintain CBF. ICPs are usually treated when above $20 \mathrm{~mm} \mathrm{Hg}$. Mean arterial pressures are often titrated to maintain a CPP above $40 \mathrm{~mm} \mathrm{Hg}$ as a study by Downard et $\mathrm{al}^{22}$ reported no survivors of 118 patients who had a mean CPP of less than $40 \mathrm{~mm} \mathrm{Hg}$. However, ideal CPP likely varies with age, which can make standardizing treatment protocols challenging.

\section{Types of Injury}

Head injury may be grouped into primary or secondary injury, mechanism, severity, and intra-axial versus extraaxial injury. ${ }^{7}$ Primary head injury encompasses the initial, direct insult to the brain. ${ }^{9}$ Injuries include a skull fracture, intracranial hemorrhage, cortical disruption, and axonal injury. The cascade of events that occurs as a reaction to the primary head injury results in secondary head injury. Secondary head injury refers to the cascade of molecular injury mechanisms that are triggered by the initial head trauma that may occur hours to days from the initial trauma. ${ }^{7}$ These mechanisms include neurotransmitter toxicity, vascular injury, vasospasm, ischemia, edema, metabolic derangements, vascular occlusion, and free radical injury. ${ }^{7,23,24}$ Secondary head injury can result in herniation, edema, infarction, and hydrocephalus. ${ }^{9}$ Much of TBI medical management is centered on prevention of secondary head injury. Children may be at higher risk for secondary brain injury because of the structural differences in their brains, in comparison to their adult counterparts, as discussed earlier.

\section{Mechanism of Injury}

\section{Blunt Trauma}

Blunt head trauma occurs when there is direct impact to the skull. The most common mechanism in children younger than 1 year is nonaccidental trauma secondary to abuse, while motor vehicle collisions and falls account for the majority of injuries in older children. Focal damage to the underlying brain is referred to as a coup injury. While damage from the rebound movement of the brain resulting in damage, often on the opposite side of the impact, is referred to as contrecoup injury. Pediatric neuroanatomy makes children more susceptible to changes in inertia leading to higher rates of diffuse cerebral edema and parenchymal injuries.

\section{Penetrating Trauma}

Penetrating brain injuries, also referred to as open head injuries, result in penetration of the calvarium and subsequent brain injury. Mechanisms most commonly include guns and knives but can include any weapon able to penetrate the skull. In addition to the usual sequelae of head trauma, these injuries are associated with a much higher rate of infectious complications.

\section{Axonal Shearing}

Changes in the angular momentum of the head result in a broad spectrum of TBI referred to as axonal injury or shearing. Vascular injury can also occur in conjunction with axonal injury. Axonal shearing typically occurs between white matter bundles and the underlying gray matter including the deeper structures such as the basal ganglia and thalamus or within the upper brain stem. Diffuse axonal injury (DAI) commonly refers to shearing coupled with vascular injury, classically manifested as petechial hemorrhages in white matter. The severity of injury with axonal shearing is very broad and can range from benign clinical manifestations such as transient loss of consciousness to profound and persistent neurologic deficits or even death.

\section{Concussion}

Concussions are the most common form of $\mathrm{TBI}^{7}$ They are often described as a spectrum of mild-to-moderate TBI without radiographic evidence of injury. ${ }^{25-27}$ These children classically present with headaches, nausea, vomiting, concentration difficulty, personality changes, and amnesia. These symptoms results from neuronal dysfunction and axonal injury that is usually transient but in some cases can results in long-term deficits. ${ }^{28,29}$ Risk factors for long-term sequelae include ongoing clinical symptoms, repeated injury, and younger age. ${ }^{26}$ Treatment of concussions is centered on physical and cognitive rest and symptom management. ${ }^{9}$ Further information about treatment and family education is discussed later under the section Mild TBI. 


\section{Injury Severity}

\section{Mild Traumatic Brain Injury}

Mild TBI is the most common form of brain injury ( 80\%) and is defined as a Glasgow Coma Scale (GCS) of $14-15 .^{30}$ Concussion, generally classified as mild TBI, are defined as a disturbance in brain function because of a direct or indirect head trauma without acute abnormality on standard neuroimaging studies. ${ }^{25-27}$ Nonspecific signs and symptoms occur from concussion, which may or may not involve loss of consciousness. A high index of suspicion for concussion should occur with the presence of one or more of the following: headache, nausea, vomiting, gait unsteadiness, confusion, amnesia, or change in personality. ${ }^{25,26}$ Overall, $89 \%$ of patients will have a full recovery with resolution of symptoms within 7 to 10 days. ${ }^{1,29}$ A small percentage of patients may experience deterioration leading to severe neurologic dysfunction unless appropriate recognition and treatment is performed. Any child with a mild TBI should have a prompt medical examination, including a neurologic examination, to exclude associated injuries including cervical spinal injuries. There are multiple standardized instruments and scales, such as the Sport Concussion Assessment Tool version $3,{ }^{25}$ which can be utilized by medical providers to assess patients with suspected or diagnosed concussions. ${ }^{1} \mathrm{~A}$ key risk factor includes a history of previous head injury. ${ }^{1}$ The possibility of child abuse or neglect should be ruled out in all cases. Children will require both physical and mental rest after a mild TBI. Patients should abstain from any activity that requires significant mental activity including reading, computers, television, video games, puzzles, cellular phone use, and school work. ${ }^{1,31}$ Once medically cleared, resumption of academic and sports activities should be done in a supervised progressive manner to monitor for symptom exacerbation. Those children, which are completely asymptomatic and neurologically intact may be observed for several hours and discharged with a reliable caretaker who is informed of the course of recovery, timeline to return to school and athletics, and the signs and symptoms that should prompt return to the hospital. ${ }^{1}$ Follow-up with a child primary care provider or a TBI clinic, if available, should be utilized.

\section{Moderate Traumatic Brain Injury}

Approximately $10 \%$ of TBIs are classified as a moderate TBI, defined as a GCS of 9-13. These children should undergo an identical work-up as those with a mild TBI but should also have laboratory studies performed and a head CT performed when criteria outlined later in the CT section is met. These children should be admitted to a facility with neurosurgical care capabilities and will require routine neurologic monitoring. Repeat CT scanning should be limited to those children with clinical deterioration. ${ }^{32,33}$ Overall, $10 \%$ of children will deteriorate and require severe TBI management.

\section{Severe Traumatic Brain Injury}

Severe TBI is defined as a GCS of $3-8 .^{34}$ These children often suffer from multisystem injuries that require multidisciplin- ary teams for aggressive resuscitation and management as outlined later in the initial management and treatment of TBI's section.

\section{Intra-Axial and Extra-Axial Injuries}

Epidural, subdural, subarachnoid, and intraventricular hemorrhages are classified as extra-axial injuries while cerebral contusion, intracerebral hematoma, and DAI are categorized as intra-axial injuries.

\section{Subdural Hematoma}

Subdural hematomas result from tearing of the bridging veins or associated contusions with hemorrhage into the subdural space (between the dura and arachnoid membranes) and are often divided into acute ( $<3$ days), subacute (3-10 days), and chronic ( $>10$ days). These classically present with crescentshaped lesions at the surface of the brain that cover the entire hemisphere and can be associated with mass effect and cortical edema. ${ }^{9}$ Operative intervention is often indicated for neurologic decompensation or with midline shift greater than $5 \mathrm{~mm}$. Infants with an open fontanelle can be candidates for a subdural tap through their fontanelle. Acute subdural hemorrhage is often associated with an underlying brain injury and thus results in a worse prognosis than epidural hematomas.

\section{Epidural Hematoma}

Epidural hematomas are most commonly located in the middle fossa because of the injury to the middle meningeal artery resulting in bleeding into the space between the skull and dura. ${ }^{9}$ However, they may also occur in the anterior or posterior fossa. The hematoma is bound by sutures lines resulting in the classic lenticular shape on CT scan. A classic description usually involves a lucid interval followed by rapid neurologic deterioration. Children with large clots $>40 \mathrm{~mL}$ or mass effect often require evacuation.

\section{Subarachnoid Hemorrhage}

Subarachnoid bleeding in acute trauma because of the disruption of the pia-arachnoidal vasculature is often seen and is rarely due to aneurysmal bleeding. ${ }^{9}$ These typically are widely distributed and are unlikely to result in mass effect. ${ }^{9}$ Postinjury hydrocephaly should be monitored and may require ventricular shunting. Severe TBIs in the presence of a subarachnoid hemorrhage portend a poor prognosis due to cerebral vasospasm. Transcranial Doppler imaging can be utilized to diagnose vasospasm. There is little data to support the use of calcium channel blockers in children with posttraumatic vasospasm.

\section{Intraventricular Hemorrhage}

Intraventricular hemorrhage may results from an intracerebral hematoma, extension of a subarachnoid bleed, or tearing of the subependymal veins or periventricular structures. ${ }^{9}$ Atraumatic intraventricular hemorrhage can be noted in premature infants. ${ }^{9}$ 
Cerebral Contusion and Intracerebral Hematoma

Cerebral contusions are localized areas of cerebral neuronal injury and bleeding. ${ }^{9}$

\section{Diffuse Axonal Injury}

DAI is a spectrum of disorders that results from axonal damage from acceleration/deceleration or rotational forces. ${ }^{9}$ This injury was further discussed earlier under axonal shearing.

\section{Skull Fracture}

Skull fractures are associated with head trauma in 2 to $21 \%$ of children. ${ }^{35}$ Fractures can occur in a linear or stellate fashion. Fractures of the skull base are typically associated with greater force. Basilar skull fractures are classically associated with Battle signs (mastoid process ecchymoses), raccoon eyes, cerebral spinal fluid rhinorrhea (cribriform plate fracture), and otorrhea (mastoid air cell or temporal bone fracture). Despite the fact that meningitis occurs in 2 to $9 \%$, prophylactic antibiotics are not recommended because of the lack of outcome improvement and risk of resistant organism selection. ${ }^{36}$ Vaccination against Streptococcus pneumonia should be considered due to increased risk of pneumococcal-associated meningitis, however. ${ }^{37,38}$

\section{Initial Evaluation and First Line Management of Head Injury}

In January 2012, evidence-based guidelines were released for the acute management of severe TBI in infants, children, and adolescents as a means of decreasing variability in care. ${ }^{39,40}$ There is a paucity of well-designed randomized controlled trials in the pediatric trauma literature, which leaves many of the recommendations based on grades $C$ and $D$ evidence. The initial evaluation should focus on the diagnosis of a primary brain injury and prevention of secondary brain injury. ${ }^{9} \mathrm{~A}$ detailed history should be obtained whenever possible focusing on timing of trauma, presence/duration of unconsciousness, seizures, nausea/vomiting, headache, visual changes, amnesia, and confusion. ${ }^{9}$ Once stabilized, children with significant TBIs or multisystem injuries should be considered for transfer to a level 1 pediatric trauma center as studies have shown improved mortality in those children transferred. ${ }^{41-43}$

\section{Resuscitation}

All TBI's should be managed in accordance with standardized trauma protocols, which starts with the "ABCs" for airway, breathing, and circulation. The pediatric GCS or adult GCS, where appropriate, should be utilized as a global neurologic assessment. ${ }^{44}$ Any child with a GCS less than 8 or one who cannot appropriately protect their airway should be promptly intubated. ${ }^{44}$ All airways should be verified with end-tidal $\mathrm{CO}_{2}$ or capnography. Subsequent chest radiographs should be utilized to ensure appropriate placement of the endotracheal tube. Cervical spine immobilization should be undertaken when clinically indicated. Hypotension contributes to sec- ondary brain injury by decreasing the $\mathrm{CPP} .{ }^{9}$ Isotonic fluids are first line for resuscitation. ${ }^{9}$ We advocate maintenance of a hemoglobin greater than $7 \mathrm{~g} / \mathrm{dL}$ or a hematocrit greater than $21 \%$.

\section{Head Computed Tomography}

Use of head CT provides rapid identification of most lifethreatening intracranial injuries. ${ }^{9}$ Several studies have been published to assist in identifying, which children with TBIs require head CT's. ${ }^{45-47}$ Routine use of repeat CT scans without neurologic deterioration is not supported in the literature. ${ }^{32,33}$ Adherence to As Low As Reasonably Achievable (ALARA) and Image Gently should be followed to minimize the risks of radiation when imaging is deemed clinically indicated. $^{48-51}$

\section{Respiratory Monitoring and Management}

Adequate oxygenation is essential to avoid neuronal ischemia as hypoxia is the leading cause of secondary brain injury. ${ }^{9}$ Ventilation should be provided with a goal $\mathrm{PaCO}_{2}$ of 35 to $40 \mathrm{~mm} \mathrm{Hg}$. The cerebral vasculature is exquisitely sensitive to changes in $\mathrm{PaCO}_{2}$ such that hypercapnia $\left(\mathrm{PacO}_{2}>45 \mathrm{~mm} \mathrm{Hg}\right)$ can lead to significant elevations in ICP because of $\mathrm{CO}_{2}-$ induced vasodilation. Hypocapnia can result in initial transient reduction of ICP but it is not sustainable and ultimately can result in cerebral vasoconstriction and subsequent decreased CBF. Hyperventilation should be reserved as a salvage maneuver in those with obvious signs of brain stem herniation. We typically titrate $\mathrm{FIO}_{2}$ to maintain oxygen saturations greater than $93 \%$.

\section{Positioning}

Elevation of the head of bed by 15 to 20 degrees should be utilized to decrease ICP in all patients except those requiring thoracic or lumbar immobilization. In cases of spinal immobilization, the bed should be placed in reverse Trendelenburg at 30 degrees. The head should be maintained in the midline position to facilitate venous drainage. If cervical collars are utilized, they should be properly fitted so as to avoid impedance of venous drainage.

\section{Sedation and Analgesia}

Appropriate sedation and analgesia may be utilized to maintain or even decrease elevated ICP by decreasing the metabolic rate and resultant $C B F$. Sedation and analgesia should be utilized during procedures to decrease ICP spikes in response to noxious stimuli. Caution should be taken with administration of sedation and analgesia given the risk of sedative- or narcotic-related changes in CBF. Additional benefits of sedation use include minimization of the risk of seizures. ${ }^{52}$

\section{Hyperosmolar Therapy}

Hyperosmolar agents such as hypertonic saline and mannitol have been utilized to reduce brain volume and ICP. With 
initial infusion, these products result in plasma volume expansion, decreased blood viscosity and ultimately reduced cerebral blood volume. ${ }^{53}$ Ideally, these therapies are reserved for volume-resuscitated patients with signs of elevated ICP unless there are clinical signs of herniation. ${ }^{9}$ While both hypertonic saline and mannitol have been utilized, current pediatric guidelines recommend hypertonic saline administration as it increases serum osmolarity directly and may be more effective in reducing ICP than mannitol. ${ }^{32,40,54-56}$ Mannitol increases serum osmolarity by functioning as an osmotic diuretic, which can result in dehydration, electrolyte disturbances, and renal failure. ${ }^{9}$ Care must be taken to avoid hyponatremia in these patients.

\section{Temperature Regulation}

Fevers should be avoided in patients with TBI. We typically maintain a core temperature of 35 to $36^{\circ} \mathrm{C}$. Hypothermia has been utilized in patients with TBI in an attempt to decrease metabolic demand and alter secondary brain injury because of the excitotoxicity and free radical formation. ${ }^{3}$ There are no good data to support the effectiveness of hypothermia with regards to improved outcomes after TBI, however. ${ }^{3,57-59}$ Hyperthermia, on the contrary, has been demonstrated to adversely affect outcomes in patients with TBI. ${ }^{60}$ Passive rewarming of patients with mild to moderately hypothermic trauma may be indicated. ${ }^{60}$

\section{Anticonvulsant Prophylaxis}

Seizures are estimated to occur in approximately $10 \%$ of children with TBIs. ${ }^{9}$ Seizure activity results in increase metabolic demand and ultimately may contribute to secondary brain injury. ${ }^{9}$ These seizures can be divided into early posttraumatic seizures (within 7 days of injury) and late posttraumatic seizures (more than 7 days after injury). Children who are younger than 2 years, have a GCS less than 9 or are victims of nonaccidental trauma are at higher risk for early posttraumatic seizures. ${ }^{61}$ Adult literature recommends prophylaxis for the first 7 days after severe brain injuries to decrease the risk of early posttraumatic seizures. ${ }^{40,61,62}$ While use of prophylactic anticonvulsants seems to vary significantly based on provider and institutional preferences, current pediatric recommendations also support the use of prophylactic phenytoin administration. ${ }^{32,62,63}$ Anticonvulsant use does not prevent later posttraumatic seizure occurrence.

\section{Corticosteroid Prophylaxis}

There are current recommendations against the prophylactic use of corticosteroids in TBI. Currently, there is no evidence to indicate that corticosteroids decrease ICP or improve overall outcomes from TBI. ${ }^{32,64,65}$

\section{Acute Surgical Management}

After initial resuscitation and stabilization, a CT scan should be obtained promptly in all hemodynamically stable children.
Mass effect is typically considered to be greater than $5 \mathrm{~mm}$ of midline shift measured on axial CT views. The basilar cisterns should also be evaluated for compression. Neurosurgical intervention should be obtained in any child with mass effect.

\section{Intracranial Pressure Monitoring and Management}

Regardless of the lack of pediatric prospective, randomized clinical trials, the use of ICP devices has become the standard of care in the United States. ICP monitoring is currently recommended in children with a GCS less than $8 .^{32}$ International guidelines recommend ICP monitoring in all patients with survivable TBIs and abnormal CT scans as well as in selected patients, which is beyond the scope of this article. ${ }^{52,66,67}$ There has been some controversy that has arisen from the Best Trip Trial, which concluded that there was no improvement in 6 months outcomes in those patients (median age 29 years) treated with ICP monitoring versus imaging and clinical examination. ${ }^{68}$ The authors clearly state that they do not recommend against the use of ICP monitors, but rather recommend increased research on appropriate interpretation and utilization of ICP monitoring technology to improve outcomes. $^{68}$ Regardless, ICP monitoring may be supported in pediatric patients given evidence that intracranial hypertension is strongly associated with poor neurologic outcome. $^{22}$ Furthermore, ICP monitoring and aggressive treatment of intracranial hypertension has been associated with the best-reported clinical outcomes. ${ }^{69}$ In recent years, there has been a shift in focus on multimodal treatments and CPP-directed therapy rather than pure ICP-directed treatment.

One must distinguish between ICP monitors and external ventricular drain. ICP monitors solely allows for monitoring and diagnosis of elevated ICP. External ventricular drains function identically as ICP monitors but have the added benefit of being therapeutic as they allow for drainage of cerebral spinal fluid.

\section{Intracranial Hypertension Refractory to First Line Treatments}

Medically, refractory intracranial hypertension is estimated to occur in 21 to $42 \%$ of children with severe TBI. ${ }^{40}$ Higher risk therapeutic interventions may be indicated in this patient population.

\section{Decompressive Craniectomy}

The goal of decompressive craniectomy is to decrease ICP, improve CPP, and improve cerebral oxygenation. ${ }^{9}$ Children are more likely to have diffuse brain swelling after TBI and may be more amenable to early decompressive craniectomy. Decompressive craniectomy should be considered in children with severe TBI and medically refractory intracranial hypertension. Improved outcomes have been demonstrated from early decompressive craniectomy before development of extensive secondary injury. ${ }^{70-72}$ 


\section{Neuromuscular Blockage}

Neuromuscular blocking agents are second line treatments of elevated ICP after initial measures have failed. They are thought to reduce ICP by decreasing airway and intrathoracic pressure, which theoretically facilitates cerebral venous outflow. Neuromuscular blockade also decrease metabolic requirements by preventing shivering, posturing, and dyssynchronous breathing. ${ }^{73}$ Neuromuscular blockade should only be considered after verification of a secure airway in an adequately sedated patient. Use of neuromuscular blocking agents is associated with prolonged ICU stays and increased risk of nosocomial infections and therefore should be reserved for elevated ICP refractory to treatments discussed earlier.

\section{Barbiturate Therapy}

Barbiturate therapy is often a second line treatment utilized to reduce refractory ICP by decreasing brain metabolism and altering vascular tone. Free radical-mediating and membrane-stabilizing properties have also been benefits of barbiturate use. Side effect profile, including significant hypotension, is the main limitation. Barbiturates have been successful in control of refractory intracranial hypertension in nearly $30 \%$ of patients. ${ }^{34}$

\section{Hyperventilation}

As discussed earlier, the typical ventilation goals in patients with TBI are $\mathrm{PaCO}_{2}$ of 35 to $40 \mathrm{~mm} \mathrm{Hg}$. Because of the risks of hypocapnic vasoconstriction, routine hyperventilation is not supported. Furthermore, hyperventilation may decrease cerebral oxygenation, resulting in ischemia. ${ }^{74,75}$ Aggressive hyperventilation $\left(\mathrm{PaCO}_{2}<30 \mathrm{~mm} \mathrm{Hg}\right.$ ) should only be considered for salvage attempts in refractory intracranial hypertension. ${ }^{9}$ Transient reductions in ICP because of hypocapnia are often not sustainable.

\section{Lumbar drain}

Placement of a lumbar drain may be considered. It is recommended that patients have a working ventriculostomy in place or CT evidence of open basilar cisterns.

\section{Conclusion}

In conclusion, TBI is an important cause of significant morbidity and mortality in children resulting in a broad spectrum of injuries patterns. The treatment of pediatric TBI should be distinguished from treatment of adult TBI. Treatment of TBI is truly multimodal and multidisciplinary and when possible, should involve pediatric specialists specifically trained in pediatric trauma.

\section{References}

1 Garcia-Rodriguez JA, Thomas RE. Office management of mild head injury in children and adolescents. Can Fam Physician 2014;60(6): 523-531, e294-e303
2 Geyer K, Meller K, Kulpan C, Mowery BD. Traumatic brain injury in children: acute care management. Pediatr Nurs 2013;39(6): 283-289

3 Perman SM, Goyal M, Neumar RW, Topjian AA, Gaieski DF. Clinical applications of targeted temperature management. Chest 2014; 145(2):386-393

4 Adekoya N, Thurman DJ, White DD, Webb KW. Surveillance for traumatic brain injury deaths-United States, 1989-1998. MMWR Surveill Summ 2002;51(10):1-14

5 Langlois JA, Rutland-Brown W, Thomas KE. The incidence of traumatic brain injury among children in the United States: differences by race. J Head Trauma Rehabil 2005;20(3):229-238

6 Langlois JA, Rutland-Brown W, Wald MM. The epidemiology and impact of traumatic brain injury: a brief overview. J Head Trauma Rehabil 2006;21(5):375-378

7 Hu CF, Fan HC, Chang CF, Chen SJ. Current approaches to the treatment of head injury in children. Pediatr Neonatol 2013;54(2): 73-81

8 Andersson EE, Sejdhage R, Wage V. Mild traumatic brain injuries in children between $0-16$ years of age: a survey of activities and places when an accident occurs. Dev Neurorehabil 2012;15(1): 26-30

9 Wing R, James C. Pediatric head injury and concussion. Emerg Med Clin North Am 2013;31(3):653-675

10 Meehan WP III, Taylor AM, Proctor M. The pediatric athlete: younger athletes with sport-related concussion. Clin Sports Med 2011;30(1):133-144, $x$

11 Muizelaar JP, Marmarou A, DeSalles AA, et al. Cerebral blood flow and metabolism in severely head-injured children. Part 1: Relationship with GCS score, outcome, ICP, and PVI. J Neurosurg 1989; 71(1):63-71

12 Shapiro K, Marmarou A. Clinical applications of the pressurevolume index in treatment of pediatric head injuries. J Neurosurg 1982;56(6):819-825

13 Bouma GJ, Muizelaar JP. Evaluation of regional cerebral blood flow in acute head injury by stable xenon-enhanced computerized tomography. Acta Neurochir Suppl (Wien) 1993;59:34-40

14 Bouma GJ, Muizelaar JP. Cerebral blood flow in severe clinical head injury. New Horiz 1995;3(3):384-394

15 Bouma GJ, Muizelaar JP, Choi SC, Newlon PG, Young HF. Cerebral circulation and metabolism after severe traumatic brain injury: the elusive role of ischemia. J Neurosurg 1991;75(5):685-693

16 Cold GE. Cerebral blood flow in the acute phase after head injury. Part 2: Correlation to intraventricular pressure (IVP), cerebral perfusion pressure (CPP), $\mathrm{PaCO}$, ventricular fluid lactate, lactate/pyruvate ratio and pH. Acta Anaesthesiol Scand 1981;25(4): 332-335

17 Jaggi JL, Obrist WD, Gennarelli TA, Langfitt TW. Relationship of early cerebral blood flow and metabolism to outcome in acute head injury. J Neurosurg 1990;72(2):176-182

18 Cruz J, Jaggi JL, Hoffstad OJ. Cerebral blood flow, vascular resistance, and oxygen metabolism in acute brain trauma: redefining the role of cerebral perfusion pressure? Crit Care Med 1995;23(8): $1412-1417$

19 Lang EW, Lagopoulos J, Griffith J, et al. Cerebral vasomotor reactivity testing in head injury: the link between pressure and flow. J Neurol Neurosurg Psychiatry 2003;74(8):1053-1059

20 Paulson OB, Strandgaard S, Edvinsson L. Cerebral autoregulation. Cerebrovasc Brain Metab Rev 1990;2(2):161-192

21 Vavilala MS, Muangman S, Tontisirin N, et al. Impaired cerebral autoregulation and 6-month outcome in children with severe traumatic brain injury: preliminary findings. Dev Neurosci 2006;28(4-5):348-353

22 Downard C, Hulka F, Mullins RJ, et al. Relationship of cerebral perfusion pressure and survival in pediatric brain-injured patients. J Trauma 2000;49(4):654-658, discussion 658-659

23 Choi DW. Excitotoxic cell death. J Neurobiol 1992;23(9): 1261-1276 
24 Choi DW, Maulucci-Gedde M, Kriegstein AR. Glutamate neurotoxicity in cortical cell culture. J Neurosci 1987;7(2):357-368

25 Guskiewicz KM, Register-Mihalik J, McCrory P, et al. Evidencebased approach to revising the SCAT2: introducing the SCAT3. Br J Sports Med 2013;47(5):289-293

26 Giza CC, Kutcher JS, Ashwal S, et al. Summary of evidence-based guideline update: evaluation and management of concussion in sports: report of the Guideline Development Subcommittee of the American Academy of Neurology. Neurology 2013;80(24): 2250-2257

27 McCrory P, Meeuwisse W, Johnston K, et al. Consensus Statement on Concussion in Sport: the 3rd International Conference on Concussion in Sport held in Zurich, November 2008. Br J Sports Med 2009;43(Suppl 1):i76-i90

28 Keightley ML, Côté P, Rumney P, et al. Psychosocial consequences of mild traumatic brain injury in children: results of a systematic review by the International Collaboration on Mild Traumatic Brain Injury Prognosis. Arch Phys Med Rehabil 2014;95(3, Suppl): S192-S200

29 Hung R, Carroll LJ, Cancelliere C, et al. Systematic review of the clinical course, natural history, and prognosis for pediatric mild traumatic brain injury: results of the International Collaboration on Mild Traumatic Brain Injury Prognosis. Arch Phys Med Rehabil 2014;95(3, Suppl):S174-S191

30 Teasdale G, Gentleman D. The description of 'conscious level': a case for the Glasgow Coma Scale. Scott Med J 1982;27(1):7-9

31 Purcell LK; Canadian Paediatric Society, Healthy Active Living and Sports Medicine Committee. Evaluation and management of children and adolescents with sports-related concussion. Paediatr Child Health (Oxford) 2012;17(1):31-34

32 Bell MJ, Kochanek PM. Pediatric traumatic brain injury in 2012: the year with new guidelines and common data elements. Crit Care Clin 2013;29(2):223-238

33 Figg RE, Stouffer CW, Vander Kolk WE, Connors RH. Clinical efficacy of serial computed tomographic scanning in pediatric severe traumatic brain injury. Pediatr Surg Int 2006;22(3): 215-218

34 Mellion SA, Bennett KS, Ellsworth GL, et al. High-dose barbiturates for refractory intracranial hypertension in children with severe traumatic brain injury. Pediatr Crit Care Med 2013;14(3):239-247

35 Bin SS, Schutzman SA, Greenes DS. Validation of a clinical score to predict skull fracture in head-injured infants. Pediatr Emerg Care 2010;26(9):633-639

36 Rathore MH. Do prophylactic antibiotics prevent meningitis after basilar skull fracture? Pediatr Infect Dis J 1991;10(2):87-88

37 Villalobos T, Arango C, Kubilis P, Rathore M. Antibiotic prophylaxis after basilar skull fractures: a meta-analysis. Clin Infect Dis 1998; 27(2):364-369

38 Ratilal BO, Costa J, Sampaio C, Pappamikail L. Antibiotic prophylaxis for preventing meningitis in patients with basilar skull fractures. Cochrane Database Syst Rev 2011;(8):CD004884

39 Timmons SD. An update on traumatic brain injuries. J Neurosurg Sci 2012;56(3):191-202

40 Kochanek PM, Carney N, Adelson PD, et al; American Academy of Pediatrics-Section on Neurological Surgery; American Association of Neurological Surgeons/Congress of Neurological Surgeons; Child Neurology Society; European Society of Pediatric and Neonatal Intensive Care; Neurocritical Care Society; Pediatric Neurocritical Care Research Group; Society of Critical Care Medicine; Paediatric Intensive Care Society UK; Society for Neuroscience in Anesthesiology and Critical Care; World Federation of Pediatric Intensive and Critical Care Societies. Guidelines for the acute medical management of severe traumatic brain injury in infants, children, and adolescents-second edition. Pediatr Crit Care Med 2012;13(Suppl 1):S1-S82

41 Johnson DL, Krishnamurthy S. Send severely head-injured children to a pediatric trauma center. Pediatr Neurosurg 1996;25(6): 309-314
42 Hulka F, Mullins RJ, Mann NC, et al. Influence of a statewide trauma system on pediatric hospitalization and outcome. J Trauma 1997; 42(3):514-519

43 Potoka DA, Schall LC, Gardner MJ, Stafford PW, Peitzman AB, Ford HR. Impact of pediatric trauma centers on mortality in a statewide system. J Trauma 2000;49(2):237-245

44 Cicero MX, Cross KP. Predictive value of initial Glasgow coma scale score in pediatric trauma patients. Pediatr Emerg Care 2013;29(1): $43-48$

45 Dunning J, Daly JP, Lomas JP, Lecky F, Batchelor J, Mackway-Jones K; Children's head injury algorithm for the prediction of important clinical events study group. Derivation of the children's head injury algorithm for the prediction of important clinical events decision rule for head injury in children. Arch Dis Child 2006; 91(11):885-891

46 Osmond MH, Klassen TP, Wells GA, et al; Pediatric Emergency Research Canada (PERC) Head Injury Study Group. CATCH: a clinical decision rule for the use of computed tomography in children with minor head injury. CMAJ 2010;182(4):341-348

47 Kuppermann N, Holmes JF, Dayan PS, et al; Pediatric Emergency Care Applied Research Network (PECARN). Identification of children at very low risk of clinically-important brain injuries after head trauma: a prospective cohort study. Lancet 2009;374(9696): $1160-1170$

48 Goske MJ, Applegate KE, Boylan J, et al. The 'Image Gently' campaign: increasing CT radiation dose awareness through a national education and awareness program. Pediatr Radiol 2008;38(3):265-269

49 The ALARA. The ALARA (as low as reasonably achievable) concept in pediatric CT intelligent dose reduction. Multidisciplinary conference organized by the Society of Pediatric Radiology. August 1819, 2001. Pediatr Radiol 2002;32(4):217-313

50 Slovis TL. Children, computed tomography radiation dose, and the As Low As Reasonably Achievable (ALARA) concept. Pediatrics 2003;112(4):971-972

51 Slovis TL. The ALARA concept in pediatric CT: myth or reality? Radiology 2002;223(1):5-6

52 Stocchetti N, Maas AI. Traumatic intracranial hypertension. N Engl J Med 2014;370(22):2121-2130

53 Ropper AH. Hyperosmolar therapy for raised intracranial pressure. N Engl J Med 2012;367(8):746-752

54 Kamel H, Navi BB, Nakagawa K, Hemphill JC III, Ko NU. Hypertonic saline versus mannitol for the treatment of elevated intracranial pressure: a meta-analysis of randomized clinical trials. Crit Care Med 2011;39(3):554-559

55 Fisher B, Thomas D, Peterson B. Hypertonic saline lowers raised intracranial pressure in children after head trauma. J Neurosurg Anesthesiol 1992;4(1):4-10

56 Simma B, Burger R, Falk M, Sacher P, Fanconi S. A prospective, randomized, and controlled study of fluid management in children with severe head injury: lactated Ringer's solution versus hypertonic saline. Crit Care Med 1998;26(7):1265-1270

57 Clifton GL, Miller ER, Choi SC, et al. Lack of effect of induction of hypothermia after acute brain injury. N Engl J Med 2001;344(8): 556-563

58 Hutchison JS, Ward RE, Lacroix J, et al; Hypothermia Pediatric Head Injury Trial Investigators and the Canadian Critical Care Trials Group. Hypothermia therapy after traumatic brain injury in children. N Engl J Med 2008;358(23):2447-2456

59 Adelson PD, Ragheb J, Kanev P, et al. Phase II clinical trial of moderate hypothermia after severe traumatic brain injury in children. Neurosurgery 2005;56(4):740-754, discussion 740-754

60 Jones PA, Andrews PJ, Midgley S, et al. Measuring the burden of secondary insults in head-injured patients during intensive care. J Neurosurg Anesthesiol 1994;6(1):4-14

61 Liesemer K, Bratton SL, Zebrack CM, Brockmeyer D, Statler KD. Early post-traumatic seizures in moderate to severe pediatric traumatic brain injury: rates, risk factors, and clinical features. J Neurotrauma 2011;28(5):755-762 
62 Chang BS, Lowenstein DH; Quality Standards Subcommittee of the American Academy of Neurology. Practice parameter: antiepileptic drug prophylaxis in severe traumatic brain injury: report of the Quality Standards Subcommittee of the American Academy of Neurology. Neurology 2003;60(1):10-16

63 Lewis RJ, Yee L, Inkelis SH, Gilmore D. Clinical predictors of posttraumatic seizures in children with head trauma. Ann Emerg Med 1993;22(7):1114-1118

64 Fanconi S, Klöti J, Meuli M, Zaugg H, Zachmann M. Dexamethasone therapy and endogenous cortisol production in severe pediatric head injury. Intensive Care Med 1988;14(2):163-166

65 Klöti J, Fanconi S, Zachmann M, Zaugg H. Dexamethasone therapy and cortisol excretion in severe pediatric head injury. Childs Nerv Syst 1987;3(2):103-105

66 Bratton SL, Chestnut RM, Ghajar J, et al; Brain Trauma Foundation; American Association of Neurological Surgeons; Congress of Neurological Surgeons; Joint Section on Neurotrauma and Critical Care, AANS/CNS. Guidelines for the management of severe traumatic brain injury. VI. Indications for intracranial pressure monitoring. J Neurotrauma 2007;24(Suppl 1):S37-S44 Erratum in: J Neurotrauma 2008;25(3):276-8

67 Maas AI, Dearden M, Teasdale GM, et al; European Brain Injury Consortium. EBIC-guidelines for management of severe head injury in adults. Acta Neurochir (Wien) 1997;139(4):286-294

68 Chesnut RM, Temkin N, Carney N, et al; Global Neurotrauma Research Group. A trial of intracranial-pressure monitoring in traumatic brain injury. N Engl J Med 2012;367(26):2471-2481
69 Tilford JM, Aitken ME, Anand KJ, et al. Hospitalizations for critically ill children with traumatic brain injuries: a longitudinal analysis. Crit Care Med 2005;33(9):2074-2081

70 Güresir E, Schuss P, Seifert V, Vatter H. Decompressive craniectomy in children: single-center series and systematic review. Neurosurgery 2012;70(4):881-888, discussion 888-889

71 Oluigbo CO, Wilkinson CC, Stence NV, Fenton LZ, McNatt SA, Handler $\mathrm{MH}$. Comparison of outcomes following decompressive craniectomy in children with accidental and nonaccidental blunt cranial trauma. J Neurosurg Pediatr 2012;9(2): 125-132

72 Pérez Suárez E, Serrano González A, Pérez Díaz C, García Salido A, Martínez de Azagra Garde A, Casado Flores J. Decompressive craniectomy in 14 children with severe head injury: clinical results with long-term follow-up and review of the literature. J Trauma 2011;71(1):133-140

73 Hsiang JK, Chesnut RM, Crisp CB, Klauber MR, Blunt BA, Marshall LF. Early, routine paralysis for intracranial pressure control in severe head injury: is it necessary? Crit Care Med 1994;22(9): 1471-1476

74 Skippen P, Seear M, Poskitt K, et al. Effect of hyperventilation on regional cerebral blood flow in head-injured children. Crit Care Med 1997;25(8):1402-1409

75 Stringer WA, Hasso AN, Thompson JR, Hinshaw DB, Jordan KG. Hyperventilation-induced cerebral ischemia in patients with acute brain lesions: demonstration by xenon-enhanced CT. AJNR Am J Neuroradiol 1993;14(2):475-484 